DOI: $10.5216 /$ racs.v6.66704

\title{
O papel dos docentes indígenas na consolidação do currículo intercultural da educação escolar do povo Pipipã
}

\section{Luiz Carlos Barbosa de Sá ${ }^{1}$ \\ Saulo Ferreira Feitosa ${ }^{2}$}

RESUMO

Este estudo trata de uma análise sobre o Projeto Político Pedagógico e o regimento escolar construídos coletivamente pelo povo Pipipã, localizado no Sertão do estado de Pernambuco, a fim de contribuir com o fortalecimento da identidade cultural do povo e seu processo de luta pela terra. O objetivo é compreender, por meio de pesquisa de campo, análise documental e TCCs, a práxis dos professores responsáveis pela consolidação do currículo intercultural indígena, a partir da valorização dos conhecimentos próprios. Os docentes Pipipã entrevistados relataram suas práticas nas quatro escolas localizadas no território e, na opinião deles, a formação inicial e continuada é fundamental para a aquisição de um pensamento crítico e politizado, dentro de uma dinâmica cultural. Os estudos empíricos sobre o movimento de resistência indígena Pipipã, por meio da educação escolar indígena, caminharam junto com a perspectiva do Pensamento Decolonial. Cada projeto político pedagógico desenvolvido para as escolas Pipipã orienta como os docentes devem trabalhar a formação dos futuros guerreiros e guerreiras, considerando alternativas para superar as tensões entre os conhecimentos originários do povo e as epistemologias impostas.

PALAVRAS-CHAVE: Professor indígena. Formação. Currículo Intercultural. Povo Pipipã.

\section{The role of indigenous teachers in the consolidation of the intercultural curriculum of the Pipipã people's school education}

\section{ABSTRACT}

This study deals with an analysis of the Political Pedagogical Project and the school regiment collectively constructed by the Pipipã people, located in the Sertão of the state of Pernambuco, in order to contribute to the strengthening of the cultural identity of the people and their process of struggle for land. The objective is to understand, through field research, documentary analysis and TCCs, the praxis of the teachers responsible for the consolidation of the indigenous intercultural curriculum, from the valorization of their own knowledge. The Pipipã teachers interviewed reported their practices in the four schools located in the territory, in their opinion, initial and continued training is fundamental for the acquisition of a critical and politicized thought of formation, within a cultural dynamic. Empirical studies on the Pipipã indigenous resistance movement, through indigenous school education, walked together with the perspective of Decolonial Thought. Each pedagogical political

\footnotetext{
${ }^{1}$ Universidade Federal de Pernambuco (UFPE), Recife, Pernambuco, Brasil. E-mail: luiz.cbsa@ufpe.br.

${ }^{2}$ Universidade Federal de Pernambuco (UFPE), Recife, Pernambuco, Brasil. E-mail: sauloffeitosa@gmail.com.
} 
project developed for pipipã schools guides how teachers should work on the training of future warriors and warriors, considering alternatives to overcome the tensions between the knowledge originating from the people and the epistemologies imposed.

KEYWORDS: Indigenous teacher. Training. Intercultural Curriculum. Pipipã people.

\section{El papel de los maestros indígenas en la consolidación del currículo intercultural de la educación escolar del pueblo pipipã}

\section{RESUMEN}

Este estudio trata sobre un análisis del Proyecto Pedagógico Político y del regimiento escolar construido colectivamente por el pueblo Pipipã, ubicado en el Sertão del estado de Pernambuco, con el fin de contribuir al fortalecimiento de la identidad cultural del pueblo y su proceso de lucha por la tierra. El objetivo es comprender, a través de la investigación de campo, el análisis documental y las ECT, la praxis de los profesores responsables de la consolidación del currículo intercultural indígena, desde la valorización de sus propios conocimientos. Los profesores de Pipipã entrevistados informaron de sus prácticas en las cuatro escuelas ubicadas en el territorio, en su opinión, la formación inicial y continua es fundamental para la adquisición de un pensamiento crítico y politizado de formación, dentro de una dinámica cultural. Estudios empíricos sobre el movimiento de resistencia indígena Pipipã, a través de la educación escolar indígena, caminaron junto con la perspectiva del Pensamiento Decolonial. Cada proyecto político pedagógico desarrollado para las escuelas pipipã guía cómo los maestros deben trabajar en la formación de futuros guerreros y guerreros, considerando alternativas para superar las tensiones entre el conocimiento originado por el pueblo y las epistemologías impuestas.

PALABRAS CLAVE: Profesor indígena. Entrenamiento. Currículo Intercultural. Gente Pipipã.

\section{Introdução}

Os docentes que atuam nas quatro escolas do povo Pipipã, no município de Floresta, sertão do estado de Pernambuco, devem ser indígenas e manter uma boa relação com a comunidade. Algo que não parece difícil, já que são partes integrantes das aldeias onde lecionam, pelos laços de parentesco. Para ser um educador Pipipã é preciso valorizar a cultura, crença e tradição, respeitando a comunidade como um todo e ter conhecimento das histórias dos antepassados. Cabe a estes professores promoverem o diálogo entre os conhecimentos contidos nos livros didáticos (escritos por não indígenas) e os conteúdos próprios do povo que, na concepção das lideranças, devem ser priorizados na educação escolar indígena. 
Essas informações foram obtidas, empiricamente, das respostas contidas em questionários com perguntas autobiográficas, para entender a origem e o lugar daqueles agentes protagonistas de uma educação escolar indígena específica e diferenciada. As questões foram propostas com a intenção de permitir que dissertassem sobre a educação escolar Pipipã, em um contexto intercultural. Além das entrevistas formais no ambiente escolar, também gravamos entrevistas informais com moradores das aldeias e lideranças do povo.

O uso de seus nomes na publicação foi assegurado pelo termo de consentimento disponível no link do comitê de ética do site da $\mathrm{UFPE}^{3}$. O documento impresso foi aplicado, preenchido e assinado pelas partes. O termo representa não só o consentimento oficial, mas o cuidado que se deve ter com o outro, respeitar a subjetividade. No entanto, os participantes deixaram claro que poderiam ser identificados. Com isso, os professores autores de trabalhos acadêmicos tiveram o direito autoral reconhecido.

Nas demais visitas, conversamos coletivamente com professores e alunos, utilizando uma técnica inspirada no Grupo Focal, isto é, “um conjunto de pessoas selecionadas e reunidas por pesquisadores para discutir e comentar um tema que é objeto da pesquisa, a partir de sua experiência pessoal" (GATTI, 2005, p. 7). Os professores participantes haviam concluído a Licenciatura Intercultural Indígena oferecida pela Universidade Federal de Pernambuco (UFPE), então, o debate partiu da análise teórica dessa formação superior com a vivência de cada PPP desenvolvido, pelos mesmos docentes, nas escolas indígenas Pipipã.

A pesquisa é justificada pelo ineditismo do tema e pelas contribuições das experiências locais dessa educação para outros povos. A Interculturalidade se constitui no principal eixo da educação escolar Pipipã, que compreendido de maneira transversal, aposta na diversidade étnica e cultural como uma maneira de vivenciar o devido respeito a outras formas de viver, pensar e conviver entre diferentes povos. Dessa forma, os professores inserem os alunos em outras realidades culturais. Após o Ensino Médio, os jovens Pipipã devem estar preparados para o mundo lá fora, prontos para usar os conhecimentos e as novas vivências artísticas, científicas e tecnológicas, não perdendo sua identidade enquanto povo Pipipã.

\footnotetext{
${ }^{3}$ O Comitê de Ética em Pesquisa - CEP é uma instância colegiada da Universidade Federal de Pernambuco, de natureza consultiva, deliberativa, educativa, autônoma, para emissão de pareceres sobre protocolos de pesquisas, vinculada a Comissão Nacional de Ética em Pesquisa - CONEP e tem por finalidade o acompanhamento das pesquisas envolvendo seres humanos, preservando os aspectos éticos primariamente em defesa da integridade e dignidade dos sujeitos da pesquisa, individual ou coletivamente considerados, levando-se em conta o pluralismo moral da sociedade brasileira. Ver mais em: https://www.ufpe.br/cep.
} 
No contexto da educação escolar dos povos indígenas, a interculturalidade é entendida como o fortalecimento das identidades étnicas. Por esse motivo, as lideranças Pipipã concebem que o fato do professor ser indígena não basta, é preciso que participem dos rituais sagrados além dos muros da escola. A primeira regra da educação escolar do povo é que seja um guerreiro formando outro.

Mas será que o professor Pipipã recebe uma formação escolar indígena que atenda à organização do seu povo, sustentada pelas lutas no âmbito das discussões sobre demarcação da terra, saúde, organização sociopolítica e reivindicação por políticas públicas outras? Essa foi a problemática de uma pesquisa de mestrado em educação, desenvolvida entre os anos de 2018 e 2020 pelo Centro Acadêmico do Agreste (CAA), Campus da Universidade Federal de Pernambuco, no município de Caruaru. A partir da aplicação dos primeiros questionários que traçavam a autobiografia de cada professor participante da pesquisa, observamos que a maioria cursou graduações convencionais em pedagogia, geografia, história, letras e ciências biológicas.

A primeira oportunidade dos professores Pipipã fazerem um curso superior específico surgiu em 2013, quando teve início a segunda turma da Licenciatura Intercultural Indígena no Centro Acadêmico do Agreste da UFPE. Até agora, oito professores que atuam nas quatro escolas do povo cursaram a graduação na Licenciatura Intercultural Indígena. Uma formação importante para o fortalecimento da identidade cultural e política dos discentes do povo.

\section{O paradigma das legislações na educação escolar indígena como enfrentamento à matriz epistêmica ocidental}

No passado, a missão educacional de "civilizar" as populações indígenas não obteve sucesso e a reforma Pombalina gerou conflitos entre alguns povos e os colonizadores portugueses em meados do século XVIII. A reforma marca a “intervenção pioneira do Estado português, que precisava dos índios nas suas lutas como aliados, a fim de garantir os seus limites externos" (FERREIRA, 2018, p. 44), cuja visão econômica era se libertar da Inglaterra, a partir de intervenções nas colônias.

Dessa forma, a educação foi usada como um elo entre colônia e colonizador, neste contexto, o verdadeiro e talvez único papel fosse o de educar, numa época em que o olhar crítico não existia. A educação durante a administração pombalina era voltada para a modernização da ordem política de Portugal no Iluminismo. Segundo Nóvoa (1998), neste 
período a escola passou a ser o instrumento para forjar a solidariedade nacional no contexto de invenção de uma cidadania que se passou a pensar ao nível do Estado-nação.

Assim, é possível defender-se que a questão colonial está também ela inscrita no coração da produção da realidade do modelo de Estado-nação e do papel que a escola desempenhou: "A Europa construiu as colônias, da mesma maneira que as colônias foram essenciais à produção do pensamento ocidental com os seus respectivos modelos de educação" (NÓVOA, 1998, p. 91-92).

Para Baniwa (2006), o processo de formação dos povos indígenas serve para identificar a diferença entre os processos educativos tradicionais e aqueles da educação escolar ofertada a eles pelo Estado brasileiro, desde que chegaram os primeiros portugueses a estas terras.

\footnotetext{
Assim, a educação indígena refere-se aos processos próprios de transmissão e produção dos conhecimentos dos povos indígenas, enquanto a educação escolar indígena diz respeito aos processos de transmissão e produção dos conhecimentos não-indígenas e indígenas por meio da escola, que é uma instituição própria dos povos colonizadores (BANIWA, 2006, p. 134).
}

A Constituição Federal de 1988 foi um histórico divisor de águas com a garantia dos direitos indígenas. Ela rompeu com a perspectiva da incorporação dos indígenas à comunhão nacional que estava prevista desde a Constituição de 1934. Desde lá, todas as constituições afirmavam que era dever do estado legislar sobre a incorporação dos índios a essa comunhão, com isso, o Estado brasileiro, a legislação e as políticas indigenistas ficavam necessariamente amarrados à perspectiva integracionista. A "Constituição Cidadã" dedicou um capítulo e três artigos à temática indígena, em especial, à garantia de uma Educação Escolar Indígena, bilíngue, intercultural, específica e diferenciada.

O artigo 231 assegura o reconhecimento da organização social, costumes, línguas, crenças e tradições. Enquanto o artigo 232 garante a legitimidade jurídica dos índios e suas comunidades como defensores de seus direitos e interesses. Já artigo $210, \S 2^{\circ}$ determina "a utilização de suas línguas maternas e processos próprios de aprendizagem”.

O novo modelo constitucional foi um meio legal de liberar as amarras da tutela do Estado e possibilitar as discussões interculturais, já que possibilita pensar outro modelo de Estado, de excludente para inclusivo, de monocultural para pluriétnico. Do ponto de vista cultural, as demais culturas existentes passaram a ser consideradas, dando um passo importante para a construção futura de um "Estado Plurinacional” (LACERDA, 2014). 
O rompimento com o clássico modelo homogêneo de Estado-Nação no Brasil propõe a abertura de um diálogo intercultural, mas ainda não possibilita integralmente a emancipação social dos grupos que compõem a diversidade étnico-cultural do país. O êxito depende justamente desses grupos, no nosso caso em análise, os professores indígenas.

Nelson Maldonado-Torres (2008) vai chamar de "Giro decolonial" todo este movimento teórico de resistência política e epistemológica à lógica moderna e eurocêntrica que têm produzido tecnologias de silenciamento marcados pela colonialidade. Ele lembra que "a descolonização não pode ser realizada sem uma mudança no sujeito" (MALDONADOTORRES, 2008, p. 68).

\section{A Licenciatura Intercultural da UFPE na formação decolonial do docente indígena}

A constituição de 1988 possibilitou a criação da Licenciatura Intercultural Indígena com a finalidade social de atender às demandas de formação de professores e professoras das escolas indígenas da rede estadual de ensino do estado de Pernambuco. De acordo com o Projeto Político Pedagógico do curso, foi constatada a necessidade de licenciar professores e professoras indígenas para atuarem nas salas de aula nos anos finais do ensino fundamental e do ensino médio:

\footnotetext{
Partiu-se do princípio que os professores e professoras não índios/as poderiam não ter o devido conhecimento sobre as etnias e, nestes casos, poderiam contribuir para a desagregação das culturas e dos saberes tradicionais de cada povo. Foi necessário, portanto, garantir o direito dos professores e professoras indígenas à formação superior, na perspectiva da interculturalidade, respeitando-se a história, a identidade e a organização social de cada povo. (PROJETO POLÍTICO PEDAGÓGICO DO CURSO, 2017, p. 15).
}

O edital de seleção para a segunda turma, que contemplou o povo Pipipã, foi publicado em 2013. O curso faz parte do projeto criado no âmbito da Secretaria de Educação Continuada, Alfabetização, Diversidade e Inclusão (Secadi), através do Programa de Apoio à Formação Superior e Licenciaturas Interculturais Indígenas (Prolind). O programa liberou recursos para a implantação em 16 Instituições de Educação Superior (IES), incluindo a UFPE. As três primeiras turmas em Caruaru concluíram a formação em 2012.2.

Alguns trabalhos de conclusão de curso e relatórios de estágio supervisionado, produzidos pelos discentes da Licenciatura Intercultural Indígena, traçaram o perfil do 
professor da escola Pipipã como forma de contribuir com o trabalho de autoria do povo, valorizando a episteme desses docentes enquanto autores de teorias válidas para a produção científica. Alguns trechos relatam a vivencia destes nas escolas Pipipã, demostrando como os princípios decoloniais se materializam.

Para a professora Jéssica Alves de Lima, da escola Menino Jesus, o professor Pipipã não deve perder os valores indígenas depois de formado, deve ter primeiro a formação tradicional do povo "sobre a história, lutas, tradições e também uma licenciatura para fortalecer o repasse para os estudantes dos conhecimentos próprios e outros para que possam se auto afirmar enquanto povo Pipipã diante da sociedade” (LIMA, 2017, p. 10).

Já artigo de Willianny Alves ressalta que o educador Pipipã deve levar em consideração a produção do conhecimento do educando, as dinâmicas e suas especificidades históricas e culturais "descartando a reprodução do conhecimento imposto pelos currículos que não considera a interculturalidade da educação diferenciada” (ALVES, 2018, p. 8).

O licenciado Ariston Cláudio evidenciou também que muito além da formação, o docente precisa estar adequado ao perfil de educador solicitado dentro da educação do povo Pipipã, em suas palavras: “Os mais velhos fazem a formação dos professores e os docentes introduzem, aprofundam e consolidam esses conhecimentos dentro da diversidade cultural Pipipã. Sejam histórias, toantes, território, sagrado, espiritual, cultural, dentro e fora da sala de aula" (CLÁUDIO, 2017, p. 14).

O trabalho de Wilma Cleminda da Silva reforça que a função do professor indígena não é apenas repassar os conhecimentos tradicionais do povo, o professor Pipipã deve participar dos movimentos, dentro ou fora da aldeia, dos rituais existentes no povo e das formações continuadas. Primeiro tem que ser indígena, morar na aldeia, respeitar as lideranças e a comunidade em geral, "a cultura, tradição e religiosidade do povo, participar das reuniões, ter uma formação inicial e respeitar todas as leis que regem a educação escolar indígena Pipipã” (SILVA, 2017, p. 09).

A formação obtida na licenciatura intercultural da UFPE foi importante para que os professores indígenas do povo fortalecessem os conhecimentos para a consolidação de uma educação própria. A luta por uma educação intercultural teve início quando o povo Pipipã não concordou com a condução da Educação Escolar conduzida pelo município de Floresta que se preocupava apenas em transmitir conhecimentos formais, então, partiu para o enfrentamento, o que podemos classificar como uma "luta local".

No início de 2002, toda a comunidade se posicionou em frente à escola Joaquim Rosendo dos Santos e os pais foram dizendo aos professores que iam chegando para trabalhar 
que a partir daquele momento eles não iriam mais ensinar aos seus filhos, "que a escola seria uma escola de índio e para índio, confrontando o município e rompendo os laços com este" (cacique Valdemir Lisboa, agosto/2017). O movimento de resistência representou a materialização da opção decolonial (QUIJANO, 2005), uma das formas de combater o racismo/sexismo epistêmico por meio da desobediência civil.

A interpretação crítica da realidade possibilitou intervir nela, nesse contexto se aplicou o questionamento a um currículo dado. Para Said (2005), a perspectiva decolonial é utilizada pelos povos colonizados para afirmar sua identidade e a existência de uma história própria (SAID, 2005, p. 13), como forma de enfrentamento ao discurso etnocêntrico dos exploradores e dos romancistas. O autor afirma: "somos ainda herdeiros desse estilo segundo o qual o indivíduo é definido pela nação, a qual, por sua vez, extrai sua autoridade de uma tradição supostamente contínua" (SAID, 2005, p. 27).

Apesar das brechas permitirem a prática de um currículo intercultural, percebemos que os professores Pipipã atuam em um campo de tensão entre a colonialidade e a decolonialidade. De um lado está o rigor do cumprimento do currículo prescrito, de outro a desobediência epistêmica, "a consciência pura da expansão europeia imperial/colonial e o convite forçado para assimilar ou para sentir a diferença colonial” (MIGNOLO, 2008, p. 304). A diferença é o que gera o pensamento de fronteira, então, vamos procurar entender agora como os docentes responsáveis por cada disciplina enfrentam esse conflito.

\section{As disciplinas específicas e diferenciadas na prática docente Pipipã}

Para entendermos os mecanismos pedagógicos que possibilitam o diálogo entre as tradições culturais e os novos conhecimentos formais, faz-se necessário pesquisarmos profundamente como o sistema de ensino da escola Pipipã é colocado em prática. A construção coletiva do Projeto Político Pedagógico, os requisitos para ingressar no quadro da educação escolar indígena na localidade (participações nos eventos culturais, religiosos e políticos do povo), a receptividade e aceitação dos estudantes à proposta da educação escolar específica, enfim, o diferencial do modelo educacional proposto no currículo intercultural, diante dos desafios e possiblidades para o fortalecimento cultural do povo.

O diálogo entre conhecimentos distintos impede a anulação de um sobre o outro. Neste contexto, a hermenêutica diatópica (SANTOS, 2003) nos possibilita entender como os povos nativos colonizados pelos europeus, como os Pipipã, adquirem o poder de um discurso 
emancipatório ao reconhecerem e fazerem reconhecer a pluralidade cultural. Mas a análise não deve ser feita numa visão binária e sim como alternativa a um mecanismo de "diálogo intercultural para a construção de um Estado plurinacional, transformador que pressupõem a descolonização das estruturas sociais, culturais e simbólicas” (PELEGRINI, 2015, p. 231242).

O Regimento Escolar Unificado das Escolas Estaduais Indígenas Pipipã estabelece esse diálogo, ao citar conteúdos que valorizam a oralidade com a comunidade por meio de conteúdos próprios sobre as plantas medicinais, o artesanato, a caça, os passos do toré etc. Os Princípios Educacionais para o Ensino Fundamental e Médio presentes no documento afirmam que as escolas indígenas Pipipã devem promover a liberdade de aprender, pesquisar e divulgar o saber do povo, "o pluralismo de ideias e de concepções pedagógicas e projetos visando à interação interdisciplinar com a participação da comunidade e assimilação dos valores indígenas, a saúde, a arte e o conhecimento global" (PERNAMBUCO, 2005, p. 4). O que prevê o documento coincide com o pensamento do coordenador pedagógico das quatro escolas Pipipã, segundo ele:

O processo de ensino de um povo não pode jamais, não levar em consideração as especificidades e as práticas culturais do povo. As crenças e tradições são trabalhadas através das práticas de alguns rituais, na contextualização dos saberes, nas palestras de lideranças e pessoas da comunidade em outros espaços educativos. (Paulo Laurentino - Coord. Pedagógico das escolas Pipipã. Agosto/2018).

O toré é a dança típica da comunidade indígena nos espaços históricos e em rituais sagrados, como por exemplo, o Aricuri, que é a expressão maior da religiosidade. Inicia-se no dia 10 de outubro e se estende até o dia 20 do mesmo mês, quando a maioria dos indígenas Pipipã se afasta do cotidiano da aldeia para um isolamento dentro da mata na Serra Negra. O período representa uma riqueza de conhecimentos extraclasse para os estudantes do povo que passam a aprender com os mais velhos, a história é contada dos antepassados até atualmente. "Lá conta como dez dias letivos, se por acaso um aluno não estiver presente leva falta, a gente se reúne com os mais velhos, fortalece os conhecimentos através desse contato com o lugar" (Estudante, dezembro de 2018).

O artigo 15 do Regimento Unificado aponta que a matriz curricular das escolas Pipipã promove um diálogo entre os conhecimentos da Base Nacional Comum com a Parte Diversificada que atenda as particularidades locais da cultura, da organização social e da economia: 
- A base comum contempla os componentes curriculares obrigatórios, no âmbito nacional, abrangendo o estudo da língua portuguesa e da matemática, o conhecimento do mundo fisico e natural, da realidade social e política.

II - A parte diversificada abrange os componentes curriculares eleitos pela comunidade escolar, como a Arte Indígena e o ensino da Lingua Estrangeira Moderna obrigatória a partir do $6^{\circ}$ ano do Ensino Fundamental.

III - O componente Arte Indígena será trabalhado pela escola de forma especifica, sendo as aulas ministradas pelos artesãos do Povo, respaldada pela orientação dos mais velhos, fortalecendo a identidade cultural do Povo.

$I V$ - No tratamento das disciplinas afins dar-se-á enfoque ao Estudo da história e Cultura Indígena e a Afro Brasileira e a Africana, conforme dispõe as leis federais $n$ ${ }^{\circ} 10.639 / 2003$ e 11.645/2008.

$V$ - A abordagem curricular em seus eixos norteadores aos temas transversais contempla temáticas relativas à Ética, a Saúde, ao Meio Ambiente, a Orientação sexual, a Auto Sustentabilidade, ao Trabalho e Consumo e a Pluralidade Cultural.

No trecho a seguir, retirado do Projeto Político Pedagógico das Escolas Pipipã, uma demonstração que a construção do documento contou com a participação da comunidade.

É necessário que seja garantido como parte constitutiva desse projeto: o respeito à organização social, memórias e histórias, medicina tradicional, territorialidade, valores e religião. Respeitando os detentores do saber garantindo aos mesmos a participação junto aos educadores do povo levando em consideração a gestão democrática (PROJETO POLÍTICO PEDAGÓGICO PIPIPÃ, 2013, p. 5).

A escola pode ser considerada como uma aliada no projeto de reivindicações e resistências do povo Pipipã, a partir de um currículo que busque atender os "saberes culturais e tradicionais numa perspectiva de fortalecer os valores da identidade étnica, formando profissionais comprometidos com as causas e lutas do povo, mas também prontos para enfrentar o mundo externo" (PROJETO POLÍTICO PEDAGÓGICO PIPIPÃ, 2013, p.2). Segundo o cacique, esse é o acordo entre as lideranças e os educadores.

A organização escolar indígena do Povo Pipipã é quem sustenta, em vários sentidos, a luta do povo, seja no âmbito das discussões sobre demarcação da terra, saúde, organização sociopolítica, reivindicação por políticas públicas outras. Em todas essas discussões o movimento das escolas se faz presente (Cacique Valdemir Lisboa, agosto de 2018).

Assim como em outros povos indígenas de Pernambuco, a educação escolar Pipipã dispõe de eixos norteadores: Terra, Organização, Identidade, História, Interculturalidade, Bilinguismo, para que os estudantes indígenas obtenham condições de desenvolver o ensinoaprendizagem dentro de sua própria realidade étnica. 
No caso Pipipã, o Ensino Médio recebe uma abordagem mais crítica nos conteúdos e nos temas transversais, exemplos como Educação em Direitos Humanos e Cidadania, Educação Ambiental, História da Cultura Pernambucana e Sertaneja, considerados conteúdos interdisciplinares, relevantes para a proposta de um currículo intercultural real. "A comunidade educacional deve articular o entrelaçamento entre trabalho, ciência, tecnologia, cultura e arte, por meio de atividades próprias as etapas do desenvolvimento humano" (PROJETO POLÍTICO PEDAGÓGICO PIPIPÃ, 2013, p.13).

Inicialmente, vamos tratar dos conteúdos específicos da educação infantil ao $9^{\circ}$ ano do Ensino Fundamental, buscando entender a práxis do PPP. O currículo para a Educação Fundamental nas quatro escolas do povo é apresentado no Projeto Político Pedagógico como "o conjunto de temas e assuntos que as crianças devem aprender, que abrange a cultura, a identidade, a arte e a natureza voltados para a realidade do povo" (PROJETO POLÍTICO PEDAGÓGICO - EDUCAÇÃO FUNDAMENTAL, 2013, p. 8).

Assim como outros povos do Nordeste, a língua materna Pipipã ficou restrita a alguns vocábulos, "em função da negação de uma série de direitos, entre os quais os direitos linguísticos" (Williany Alves, professora de Língua Materna, 2018). Dos povos indígenas de Pernambuco apenas o povo Fulni-ô, localizado no município de Águas Belas, é considerado bilíngue, desde crianças aprendem a falar o Iatê e o português, através da interação natural.

Apesar do povo não ter uma língua materna específica, as expressões próprias estão presentes inclusive nas aulas em que ocorre a interação entre os mais velhos. O Projeto Político Pedagógico afirma que conteúdos de Língua e Linguagem para a formação inicial são norteados pelo eixo norteador Bilinguismo, (vocabulário de palavras indígenas Pipipã). "Para ser um educador Pipipã se faz necessário uma formação na comunidade que os insira no conhecimento e sentidos dos vocábulos [...] a formação que se aprende na vivência indígena, em espaços outros” (Williany Alves, professora de Língua Materna, 2018).

A escola indígena Menino Jesus conta com uma importante ajuda no resgate da língua materna: o juremeiro Inácio que trabalha como auxiliar de serviços gerais no local. Todas as sextas-feiras tem um momento com ele na sala de aula, para falar sobre a religiosidade, história do povo, a natureza, a cultura, a linguagem. Um momento que ilustrou bem a importância desses encontros de aprendizagem com as lideranças, foi quando Inácio perguntou como se chamava a Serra Negra e, em seguida, as crianças responderam Kambixurú, a mata mãe; e que o nome deles enquanto crianças é curumim.

Outra forma de buscar o fortalecimento da identidade étnica e cultural é através do ensino da história local. O conteúdo próprio é trabalhado desde cedo com o objetivo não só de 
formar, mas de construir a própria identidade dos futuros guerreiros e guerreiras. O Projeto Político Pedagógico orienta que os professores devem priorizar conteúdos que resgatem a origem do povo Pipipã, a formação dos grupos familiares, onde os heróis são lideranças que já se foram. O PPP evidencia que o conteúdo de história que deve ser trabalhado remete à memória do povo. Para uma das professoras da disciplina, esse tipo de conteúdo que evidencia a vivência indígena deve ser trabalhado em espaços outros, além dos muros da escola, como por exemplo, nas aulas passeio aos espaços sagrados e tradicionais.

\footnotetext{
A gente já tinha ouvido falar da serra dos Pipipã, mas até então nunca havia passado pela nossa mente em visitar essa serra, mas fomos e foi uma das aulas que mais ocorreu momentos de aprendizagem, porque eles tiveram o contato da história com a visualização daquela área que faz parte da nossa história. Então a gente viu que foi de grande importância para os estudantes. Conseguimos reunir esses estudantes e professores para que saíssem dos muros da escola e vivenciassem essa história que estava apenas sendo contada e não vivenciada (Elisângela Rosendo, Professora de história, dezembro de 2018).
}

O Eixo Organização enxerga a educação como uma aliada para fortalecer politicamente o povo, como base de sustentação nas tradições religiosas e sociais, na perspectiva da luta pela autonomia. Em outras palavras, mas com o mesmo sentido, o PPP fala em auto-sustentação, algo que deve ser ensinado ao evidenciar nas disciplinas as formas de trabalho na aldeia (o artesanato, a caça, a agricultura, a pecuária) e sugere que sejam trabalhados nas escolas aspectos bem pessoais, como "a saída do povo da aldeia para morar na beira da estrada, a falta d'água, chegada da energia solar, projetos das casas (de alvenaria), escola de índios, de criação de bodes e história das associações” (PROJETO POLÍTICO PEDAGÓGICO, 2013, p. 9).

Os conteúdos propostos no PPP para serem trabalhados na questão da saúde estão voltados para as curas tradicionais e uso das plantas medicinais utilizadas pelos mais velhos na produção dos remédios. "Quixabeira para inflamação, leite de pinhão para sarar ferimento, imburana para acalmar quem tem problema de pressão, paud'alho que serve pra febre de criança, além de outras” (Juremeiro Inácio Francisco, outubro de 2019).

Já a proposta curricular para o trabalho pedagógico dos educadores do Ensino Médio busca promover o fortalecimento da identidade étnica, da autonomia, respeitando as concepções de pluralidade cultural de cada área do conhecimento. "Propõe servir de estímulo e apoio à reflexão sobre a prática pedagógica do professor, do planejamento à avaliação" (PROJETO POLÍTICO PEDAGÓGICO DO ENSINO MÉDIO, 2013, p. 14).

A proposta pedagógica para o Ensino Médio sugere um diálogo intercultural, na valorização dos saberes próprios. Diferente do Ensino Fundamental, os componentes curriculares do Ensino Médio se articulam em três áreas de conhecimentos. Na primeira: 
"Linguagens Códigos e suas Tecnologias" tem o objetivo de garantir estudos dos saberes/conhecimentos produzidos no povo Pipipã, as expressões linguísticas, corporais e artísticas que potencializem os conhecimentos do estudante indígena, contribuindo para que os registros dos saberes que até então eram transmitidos através da oralidade, "possam também desenvolver ações e atividades que qualifiquem as produções escritas e a comunicação dos estudantes" (Idem, 2013, p. 14).

O PPP propõe, para o eixo Ciências da Natureza, Matemática e suas Tecnologias, que o estudante Pipipã conheça e compreenda no próprio cotidiano a Matemática, transformando situações do dia a dia em suporte para o estudo da mesma, nas quais possa desenvolver os conhecimentos da etnomatemática. O conteúdo trabalhado na sala de aula sugere que matemática "faz parte da nossa vida estando presente em todos os espaços do nosso povo, na prática do plantio, na confecção de objetos, nos espaços sagrados, nas datas comemorativas entre outros" (PROJETO POLÍTICO PEDAGÓGICO DO ENSINO MÉDIO, 2013, p. 14).

Em Ciências Humanas e suas Tecnologias a meta é trabalhar a compreensão dos direitos indígenas e suas lutas, os contextos sociais, culturais, políticos e territoriais na conjuntura nacional, regional e do povo Pipipã. O Projeto Unificado das escolas sugere que o arcabouço crítico da filosofia e da sociologia incluído como disciplinas obrigatórias em todas as séries do Ensino Médio (Lei $n^{\circ} 11.684$ de 2008) viabilize a construção de "estratégias pedagógicas que possibilitam ao estudante o envolvimento do seu potencial crítico e investigativo promovendo condições onde possa desenvolver sua autonomia" (PROJETO POLÍTICO PEDAGÓGICO DO ENSINO MÉDIO, 2013, p. 04).

\section{Uma educação diferenciada requer um calendário escolar próprio}

De acordo com o Regimento Unificado das escolas Pipipã, "o período letivo é organizado na forma de calendário escolar elaborado anualmente pela coordenação, com participação colegiada dos professores, pajé, cacique e demais lideranças" (REGIMENTO UNIFICADO DAS ESCOLAS PIPIPÃ, 2005, p. 07), como forma de adequar os conhecimentos previstos na legislação vigente aos eventos religiosos e culturais da comunidade e as datas comemorativas do próprio povo.

Ainda de acordo com o PPP do ensino infantil ao Fundamental, de janeiro a junho é vivenciado o tempo de reprodução das árvores, da caça, da colheita de frutas como o catolé e safra do umbu. O documento foi elaborado considerando as primeiras chuvas do ano no Sertão: 
Em fevereiro época de chuva e plantação, em março mês de colheita, em abril comemoramos a semana dos povos indígenas e o dia de São Expedito, padroeiro de Travessão do Ouro, em maio dia das mães e festejamos o mês de Maria fazendo novenas e procissões. (PROJETO POLÍTICO PEDAGÓGICO - EDUCAÇÃO FUNDAMENTAL, 2013, p. 12).

No início do ano letivo, são vivenciados conhecimentos acerca dos tipos de plantas nativas frutíferas e medicinais, espécies vegetais usadas na confecção de casas e artesanato, as chuvas, época do preparo da terra para as plantações. Neste último item, inclui uma particularidade dos conhecimentos do povo Pipipã, "o cultivo do solo certo para o plantio de feijão de corda e arranca, fava e milho, melancia, abóbora, macaxeira, entre outras... os animais e a biodiversidade existente no Povo, tempo do mel de abelha" (PROJETO POLÍTICO PEDAGÓGICO DO EJA, 2017, p.27).

O PPP orienta que nessa época do ano sejam trabalhados em Geografia conteúdos como "agricultura, desmatamento (broca), coivara (queimada), poluição, pulverização, tipos de plantio, colheita, pecuária, vegetação e água" (PROJETO POLÍTICO PEDAGÓGICO EDUCAÇÃO FUNDAMENTAL, 2013, p.10). A parte diversificada abrange os componentes ocultados pela violência do passado e que atualmente foram eleitos pela comunidade escolar para fazer parte do currículo, na busca por uma educação intercultural de fato.

Em setembro, é lembrado que no dia 04/09/1802 foram aldeados 114 "gentios" da nação Pipipã na aldeia das missões. Em outubro, faz parte do calendário escolar o período do Aricurí entre os dias 10 e 20. No calendário do mês de dezembro é lembrado que o índio João Cabeça de Pena, guerreiro Pipipã, após receber voz de prisão foi espancado até a morte por fazendeiros locais. A matriz curricular contempla a Base Nacional Comum com os componentes curriculares obrigatórios, em âmbito nacional, e a parte diversificada.

Atualmente, o tema demarcação do território está presente, de forma interdisciplinar, nas mais variadas disciplinas, assim como as lutas da organização de mulheres do povo Pipipã que tem a finalidade de reivindicar os direitos de igualdade diante da sociedade machista. Os rituais sagrados, Jurema e Aricurí têm o objetivo de "resgatar jovens e adolescentes, trazendoos para o ritual e a escola, desenvolvendo trabalhos comunitários no povo" (PROJETO POLÍTICO PEDAGÓGICO DA ESCOLA JOAQUIM ROSENDO, 2013, p. 02).

A preocupação atual dos educadores indígenas do povo Pipipã é com as propostas do governo federal, desde a gestão passada, quanto à reforma do Ensino Médio que prevê a imposição de conteúdo em uma Base Nacional Curricular Comum a estudantes de diferentes culturas. Na opinião do cacique/educador, o novo sistema de ensino homogêneo está voltado 
para a profissionalização a partir da valorização de disciplinas voltadas para o mercado de trabalho em detrimento dos conteúdos que despertem o senso crítico no povo.

\begin{abstract}
Nos preocupa... pois corremos um sério risco das nossas escolas perderem a função dentro do povo, pois pra nós escola não tem só a função de formar cidadão, ela é um espaço de fortalecimento da identidade, de construção da personalidade. Nesse novo pensar do Ensino Médio, nós vamos ter que adotar pelo menos 40\% da nova BNCC na nossa grade curricular, pra nós, escola vai muito além disso. Com essa nova reforma, com esse novo governo que se instala, vamos perder muitas vertentes, no Regime Militar o intuito era formar técnicos, agora essa proposta começa a reacender. Quem pensa a educação, não pensa uma educação indígena na zona rural de Floresta, no sertão de Pernambuco, no semiárido (Cacique Valdemir Lisboa, dezembro de 2018).
\end{abstract}

Para Baniwa (2020), o professor indígena tem que desobedecer a ciência para continuar existindo, para permanecer de forma cultural e identitária. "A resistência pedagógica e epistêmica acontece quando se recusa o capitalismo anti-humano, a política injusta, as religiões alienadoras e a ciência colonizadora"4.

\title{
Considerações finais
}

As situações pedagógicas mostradas até aqui representam "rachaduras" no currículo Pipipã abrindo possiblidades para uma prática decolonial. Uma prática do professor indígena que abre o caminho para o direito a uma educação que ensina a viver conforme se sente, compreende a sociedade, mas prioriza a cosmopolítica, ou seja, o respeito à natureza. Afinal, o território, intrinsicamente ligado à defesa da Mãe Terra, é a base das relações transcendentais de pertencimento.

Os saberes do povo Pipipã são construídos a partir das lutas com os mais velhos, os jovens, crianças e a comunidade. Historicamente, esses ensinamentos foram ocultados durante o processo de colonização, estabelecendo demandas desses ensinamentos educativos de possíveis caminhos curriculares do que é vivido no contexto cotidiano. Trata-se do encontro das narrativas sociais e culturais de cada um na perspectiva de contribuir na formação de guerreiros críticos e conscientes.

Fica claro que as conquistas até então obtidas não cessam as demais bandeiras de lutas que encontram na educação uma forte aliada. Para a consolidação de currículo que aborde a garantia de direitos foi necessária muita luta dos educadores indígenas responsáveis pela

\footnotetext{
${ }^{4}$ Fala do professor Gersen Baniwa, durante a palestra "A Construção de uma Agenda Educacional Comum a Índios e Não Índios em Prol de um País Sócio-Ambientalmente Sustentável e Humanamente Solidário" na abertura do semestre 2020.1 do Mestrado Profissional em Ensino de História (ProfHistória) da UFPE, Campus Recife, no dia 5 de março de 2020.
} 
educação escolar Pipipã. Eles são orientados a trabalhar a autoestima do aluno indígena para torná-lo um guerreiro do povo, mas enfrentam as imposições materializadas na reforma do Ensino Médio e na BNCC.

Cabe aos professores promoverem o diálogo entre os conhecimentos regulares e os conteúdos diferenciados do povo que, na concepção do pajé Expedito Rosendo, devem ser priorizados na educação escolar. Mesmo divididos entre as determinações normativas da Secretaria Estadual de Educação e as orientações da liderança maior do povo, percebemos que os docentes Pipipã têm a consciência que a junção de diferentes saberes é importante para a formação integral diante das demandas educacionais contemporâneas e da diversidade etnocultural.

Concluímos que houve avanços do marco legal, a partir da Constituição de 1988, na construção do currículo intercultural, mas muitos(as) professores(as) que atuam na educação indígena não tiveram a mesma oportunidade de acesso a uma formação voltada para a interculturalidade. Daí a necessidade de mais programas contínuos de formação serem incorporados às discussões temáticas para implementação de políticas específicas acerca da formação de professores/as indígenas.

\section{Referências}

ALVES, Williany. A valorização da "língua materna" e dos conhecimentos tradicionais do povo nas escolas Pipipã. Artigo (Licenciatura Intercultural Indígena), Centro Acadêmico do Agreste - CAA/UFPE, 2018.

BANIWA, Gersem Luciano. O Índio Brasileiro: o que você precisa saber sobre os povos indígenas no Brasil de hoje / Gersem dos Santos Luciano - Brasília: Ministério da Educação, Secretaria de Educação Continuada, Alfabetização e Diversidade; LACED/Museu Nacional, 2006.

BRASIL. MEC. Base Nacional Comum Curricular (BNCC). 2018. Disponível em: $<$ http://historiadabncc.mec.gov.br/documentos/BNCC-APRESENTACAO.pdf >. Acesso em: 01 nov. 2018.

BRASIL. Constituição da República Federativa do Brasil de 1988. Brasília, DF, Senado, 1998. Disponível em: http://www.alep.pr.gov.br/ system/files/corpo/Con1988br.pdf.

CLÁUDIO, Ariston. Relatório de estágio supervisionado: Perfil do professor indígena Pipipã. Licenciatura Intercultural Indígena, Centro Acadêmico do Agreste /Universidade Federal de Pernambuco, Caruaru, 2017.

FERREIRA, Diana. "Primeiro nós somos Indígenas e depois nós somos Professores": educação escolar Kambiwá e identidade étnica. Dissertação (Mestrado em Educação 
Contemporânea) - Centro Acadêmico do Agreste/Universidade Federal de Pernambuco, Caruaru, 2018.

FUNAI - Fundação Nacional do Índio. Resumo do Relatório Circunstanciado de Identificação e Delimitação da Terra Indígena Pipipã (PE). Ports. N $^{\circ} 802$ PRES/FUNAI de 20/07/2005 e No 1177 PRES/FUNAI de 07/10/2008. Diário Oficial da União (DOU), Página 31 da Seção 1 , de 25 de Abril de 2017. Disponível em: ttps://www.jusbrasil.com.br/diarios/144212158/dou-secao-1-25-04-2017-pg-31.

GATTI, Bernardete. Grupo focal na pesquisa em Ciências Sociais e Humanas. Brasília: Líber Livro, 2005.

LACERDA, Rosane Freire. "Volveré, y seré millones": contribuições descoloniais dos movimentos indígenas latino americanos para a superação do mito do Estado-Nação. Tese (Doutorado), Universidade de Brasília - UnB. Brasília - DF, 2014.

LIMA, Jéssica. Relatório de estágio supervisionado III: Formação do Professor Indígena. Licenciatura Intercultural Indígena. Centro Acadêmico do Agreste/Universidade Federal de Pernambuco, Caruaru, 2017.

MALDONADO-TORRES, Nelson. "La descolonización y el giro des-colonial". Tabula Rasa, n.9, p. 61-72, Bogotá, 2008.

MIGNOLO, Walter. Desobediência epistêmica: a opção descolonial e o significado de identidade em política. In. Cadernos de Letras da UFF - Dossiê: Literatura, língua e identidade, n. 34, p. 287-324, 2008.

NÓVOA, A. Histoire \& comparaison: essais sur l'éducation. Lisboa: Educa, 1998.

PELEGRINI, I. M.; MAGALHAES, J. L. Q.; GOMES, R. N. Hermenêutica diatópica como mecanismo de diálogo intercultural para a construção de um Estado Transformador. In: International Colloquium Epistemologies of the South, Coimbra, 2014.

PERNAMBUCO. Decreto n' 27.854. Regimento Escolar Unificado - Escolas Estaduais Indígenas Pipipã, 25 de abril de 2005 - DOU 26/04/2005.

PERNAMBUCO. Projeto Político Pedagógico do Povo Pipipã, Secretaria de Educação do Estado, 2013.

SAID, Edward. Representações do intelectual. São Paulo: Companhia das Letras, 2005.

SANTOS, Boaventura de Souza. Por uma concepção multicultural de direitos humanos. In: SOUSA SANTOS, Boaventura de (org). Reconhecer para libertar: os caminhos do cosmopolitismo cultural. Rio de Janeiro: Civilização Brasileira, 2003.

SILVA, Wilma Cleminda da. Relatório de estágio supervisionado: perfil do professor indígena Pipipã. Licenciatura Intercultural Indígena. Centro Acadêmico do Agreste//Universidade Federal de Pernambuco, Caruaru, 2017. 
Submetido em 28 de abril de 2021.

Aceito em 09 de abril de 2021.

Publicado em 26 de maio de 2021. 